\title{
DIGITALISASI, ERA TANTANGAN MEDIA (Analisis Kritis Kesiapan Fakultas Dakwah Dan Komunikasi Menyongsong Era Digital)
}

\author{
Rustam Aji \\ Editor Online Tribun Jateng \\ rajif75@yahoo.com
}

\begin{abstract}
ABSTRAKSI
7 his is simply the best book that I have read on the aesthetics of new media. Other authors have often made exaggerated and superficial claims about the novelty of art and design in the new digital technologies. Manovich offers us instead a sober and yet always fresh and exciting analysis of the relationships between new media and their predecessors, especially cinema. As a practicing artist as well as a theorist and historian of media, Manovich can explain the continuities with the past. This sense of history enables him to argue convincingly for the qualities of new media that he believes are truly new.
\end{abstract}

Keywords: digital technology, challenge, media

\section{ANSTRAKSI}

Deknologi digital merupakan teknologi yang tidak lagi mengggunakan tenaga manusia atau manual. Sistem digital adalah perkembangan dari sistem analog. Digitalisasi cenderung pada sistem pengoperasian yang otomatis dengan format yang dapat dibaca oleh komputer. Perubahan sistem analog ke digital telah mengubah banyak hal dan mengancam eksistensi media cetak. Sebagian besar pelanggan media cetak telah beralih ke penggunaan teknologi on line yang lebih feksibel, bisa membaca informasi terbaru kapan saja dan dimana saja. Penyajian yang lebih hidup telah menarik pengiklan.

Kata kunci: teknologi digital , tantangan, media 
BEGITULAH pendapat Jay David Bolter, Wesley Chair of New Media, Georgia Institute of Technology, author with Richard Grusin of Remediation ketika mengomentari Lev Manovich.

Lev Monovich merupakan Professor of Visual Arts, University of California, San Diego, yang menulis buku The Language of New Media. Lev Manovich (2002) mengidentifikasi lima karakteristik digital, yakni numerik representasi; modularitas (prinsip perakitan unit yang lebih besar dari yang lebih kecil); otomatisasi; variabilitas; dan transcoding (hubungan antara komputasi dan budaya sehari-hari).

Menurutnya, teori digital selalu berkaitan erat dengan media, karena media terus berkembang seiring dengan majunya teknologi dari media lama sampai media terbaru, sehingga mempermudah manusia dalam segala bidang yang berkaitan dengan Teori Digital.

Sebaiknya kita tahu apa arti digital dalam arti yang sebenarnya, sebelum tahu apa itu Teori Digital. Digital berasal dari bahasa yunani yaitu, kata Digitus yang berarti jari jemari. Jumlah jari-jemari kita adalah 10, dan angka 10 terdiri dari angka 1 dan 0 . Oleh karena itu Digital merupakan penggambaran dari suatu keadaan bilangan yang terdiri dari angka 0 dan 1 atau off dan on (bilangan biner). Semua sistem komputer menggunakan sistem digital sebagai basis datanya. Dapat disebut juga dengan istilah Bit (Binary Digit).

Digital adalah sebuah metode yang kompleks, dan fleksibel yang membuatnya menjadi sesuatu yang pokok dalam kehidupan manusia. Sedangkan Teori Digital adalah sebuah konsep pemahaman dari perkembangan Zaman mengenai Teknologi dan Sains, dari semua yang bersifat manual menjadi otomatis ,dan dari semua yang bersifat rumit menjadi ringkas.

Dan, saat ini, era teknologi digital tengah dimulai. Semua serba teknologi. Apakah ini yang disebut era modern, era yang sudah diprediksi oleh para ilmuwan sejak dulu. Era, di mana seluruh kegiatan manusia dikendalikan oleh kecanggihan teknologi: digitalisasi!

Teknologi digital merupakan teknologi yang tidak lagi menggunakan tenaga manusia, atau manual. Tetapi cenderung pada sistem pengoperasian yang otomatis dengan sistem komputerisasi atau format yang dapat dibaca oleh komputer. Sistem digital adalah perkembangan dari sistem analog. Sebuah sistem digital menggunakan urutan angka untuk mewakili informasi. Tidak seperti sinyal analog, sinyal digital bersifat noncontinuous.

Peralihan sistem analog ke digital ini, telah mengubah banyak hal. Termasuk industri media. Kata media sendiri berasal dari bahasa latin yang memiliki arti sebagai perantara sebuah informasi dengan penerima informasi atau media perantara. Media baru secara sederhana adalah media yang terbentuk dari interaksi antara manusia dengan komputer dan internet secara 
khususnya. Contohnya sesuatu yang berhubungan dengan komputer dan internet yang di dalamnya ada social network, situs - situs web penyedia video dan audio. Bisa juga handphone di zaman sekarang ini karena mirip dengan komputer.

ini $\begin{gathered}\text { Peralihan pembaca media } \\ \text { cukup berpengaruh pada }\end{gathered}$ keberlangsungan media. Ini bisa dilihat dari sejumlah data dan fakta, bahwa sudah banyak media (cetak) yang gulung tikar karena tidak lagi diminati pembaca meski beritaberita yang disajikan bagus. Karena itu, banyak industri media yang dulu berbasis pada cetak (printed) kini sudah banyak yang beralih ke sistem online. Ini, tak lepas dari pesatnya perkembangan industri layanan internet. Yang mana, sebagian besar pelanggan media (cetak) telah beralih memanfaatkan teknologi online. Karena lebih fleksibel, bisa membaca informasi terbaru kapan dan di mana saja menggunakan smartphone berbasis android -selama ada jaringan internet. Ini berbeda dengan cetak, yang harus menunggu besoknya untuk bisa meng-update informasi baru.

Muhammad Ridlo 'Eisy adalah Ketua Harian Serikat Penerbit Suratkabar (SPS) Pusat, Direktur PT Galamedia Bandung Perkasa yang menerbitkan Harian Umum Galamedia di Bandung, sekitar tahun 2008, dalam sebuah artikelnya menuliskan bahwa para penerbit yang tergabung dalam SPS menyadari bahwa bisnis media cetak semakin berat. Senja kala korankoran Amerika Serikat (AS) diamati dengan cermat oleh seluruh penerbit Indonesia. Mulai dari bangkrutnya Chicago Tribune, Los Angeles Time, sampai dengan ditutupnya The Rocky Mountain News, Seattle Post Intelegencier, Philladephia Inquiry, Baltimore Examiner, Kentucky Post, King Country Journal, Cincinnati Post, Union City Register Tribune, Halifax Daily News, Albuquerque Tribune, South Idaho Star, San Juan Star, dan masih banyak koran-koran besar di AS yang sedang menanti keputusan untuk ditutup.

Sebagian dari koran-koran itu pindah ke media online. Jika kita buka internet, dan memasukkan kalimat "The end of Newspaper" atau "Newspaper Death Watch" dalam search engine internet, maka ratusan judul segera muncul. Semuanya mengisahkan sekaratul maut korankoran di AS.

Alasan utama dari runtuhnya media cetak di negara-negara Barat, itu adalah karena berkembangnya media baru internet. Makin banyak orang di negara-negara Barat mengunjungi media online untuk mendapatkan informasi, apalagi pada musim dingin yang penuh salju. Untuk apa harus keluar rumah untuk memungut koran pagi demi membaca berita koran, jika berita yang sama bisa dibaca melalui komputer di dalam rumah yang hangat.

\section{MAKIN MANISNYA MEDIA ONLINE}

Ibarat anak perempuan, media online tengah menjadi gadis manis yang beranjak dewasa. Digandrungi 
pria yang melihatnya! Kenapa media online sedemikian menariknya? Apakah ini berarti media cetak sudah "tamat" di era digital ini? Lalu, bagaimana menyikapi pertmbuhan media online yang 'tanpa sekat'? Dan, apa yang perlu dipersiapkan Fakultas Dakwah dan Komunikasi Universitas Islam Negeri (UIN) Walisongo dalam menghadapi fenomena era digital tersebut?

Era digital bukanlah digitalisasi konten media ke bit, tetapi kehidupan yang dinamis dari "new media" isi dan hubungan interaktif dengan konsumen media itu sendiri sebagaimana digambarkan Lev Monovich. Jadi terletak pada pengaksesannya secara real time (kapan saja dengan mudah). Jadi (New media) adalah istilah yang dimaksudkan untuk mencakup kemunculan digital, komputer, atau jaringan teknologi informasi dan komunikasi di akhir abad ke20. Sebagian besar teknologi yang digambarkan sebagai "media baru" adalah digital, seringkali memiliki karakteristik dapat dimanipulasi, bersifat jaringan, padat, mampat, interaktif dan tidak memihak. Beberapa contoh missal internet, website, komputer multimedia, permainan komputer, CD-ROMS, dan DVD.

Media online kini telah makin berkembang di masyarakat. Lewat Internet, mereka tak hanya merebut minat pembaca, tapi juga pengiklan media cetak. Bahkan, Menteri Komunikasi dan Informatika, Rudiantara, dalam acara Icon 2016 di Jakarta, menilai ini adalah era senjakala media cetak.
Indikator kemajuan media online, menurut Rudiantara, adalah moncernya kinerja keuangan perusahaan-perusahaan pelakunya. Dibanding media cetak, media digital unggul dari segi penyajian. Dengan membuka satu laman berita digital, konsumen bisa membaca teks, melihat foto, bahkan menonton video. Jika ingin berinteraksi, komentar mereka bisa seketika tersaji dan mendapat respons.

Kemudahan-kemudahan itu tentu juga menarik bagi pengiklan. Saat ini akan makin banyak pengiklan menyasar media digital. Karena, media online menawarkan kemudahan bagi pengiklan, mulai dari segi penempatan sampai pembayaran.

Hal ini diakui oleh Ari Fadyl, Kepala Bidang Transformasi dan Inovasi AXA Indonesia (TEMPO. CO, 6 Januari 2016). Di mana, di media digital, peran iklan sebagai penggiring konsumen potensial lebih efektif. Tinggal mencantumkan link, dengan satu klik, calon konsumen bisa masuk ke laman atau aplikasi perusahaan. Menurutnya ini penting bagi orang seperti dirinya yang beekerja di asuransi. Sebab untuk membeli asuransi, misalnya, orang perlu diyakinkan dengan penjelasan atau bahkan pengalaman.

Pengalaman yang dimaksud Ari, misalnya, menyediakan tes online untuk mencari bakat anak dan menemukan sekolah yang sesuai, hingga pada akhirnya para orang tua kepincut membeli asuransi pendidikan. Ia telah membuktikan efektivitasnya. 
Perusahaannya yang baru mulai terjun di digital 2 tahun lalu, sekarang sudah ada antara 7-8 juta nasabah datang dari channel tersebut.

Inti dari apa yang disampaikan Ari itu sederhana, ada perubahan besar dari media cetak ke digital. Perubahan itu memengaruhi cara kita berpikir, bersikap, atau lebih dalam lagi memengaruhi sistem neural kita. Pertanyaannya adalah, apakah medium berbeda tadi membawa konsekuensi etis atau tidak? Apakah teknologi ini akan membawa perubahan yang memiliki konsekuensi etis? Ya, mau tidak mau, atas perubahan itu, kita harus mampu menyesuaikan diri (beradaptasi), seperti halnya ketika teknologi belum secanggih sekarang. Kita pun harus menggunakan mesin ketik!

Sebetulnya, tak ada perbedaan yang terlalu signifikan antara media cetak dengan media online. Dari segi penerapan ilmu jurnalistik, struktur organisasi, dan sebagainya, nyaris semuanya sama. Mungkin hanya perlu dilakukan sedikit penyesuaian karena jenis medianya yang berbeda. Perbedaan yang paling mencolok di antara keduanya adalah mediumnya. Yang satu virtual, satunya lagi bentuk printed.

Perbedaan Teknis Media Cetak dengan Media Online:

\begin{tabular}{|c||l|l|}
\hline \multicolumn{1}{|c|}{ Unsur } & \multicolumn{1}{|c|}{ Media Cetak } & \multicolumn{1}{c|}{ Media Online } \\
\hline $\begin{array}{l}\text { Pembatasan } \\
\text { panjang naskah }\end{array}$ & $\begin{array}{l}\text { Biasanya panjang } \\
\text { naskah telah } \\
\text { dibatasi }\end{array}$ & $\begin{array}{l}\text { Tidak ada pembatasan panjang naskah, karena } \\
\text { halaman web bisa menampung naskah yang } \\
\text { sepanjang apapun. Namun demi alasan kecepatan } \\
\text { akses, keindahan desain dan alasan-alasan teknis } \\
\text { lainnya, perlu dihindarkan penulisan naskah yang } \\
\text { terlalu panjang. }\end{array}$ \\
\hline Prosedur naskah & $\begin{array}{l}\text { Naskah biasanya } \\
\text { harus di-ACC } \\
\text { oleh redaksi } \\
\text { sebelum dimuat. }\end{array}$ & $\begin{array}{l}\text { Sama saja. Namun ada sejumlah media yang } \\
\text { memperbolehkan wartawan di lapangan yang telah } \\
\text { dipercaya untuk meng-upload sendiri tulisan- } \\
\text { tulisan mereka. }\end{array}$ \\
\hline \multirow{2}{*}{ Editing } & $\begin{array}{l}\text { Kalau sudah } \\
\text { naik cetak (atau } \\
\text { sudah di-film- } \\
\text { kan pada proses } \\
\text { percetakan), tak } \\
\text { bisa diedit lagi. }\end{array}$ & $\begin{array}{l}\text { Walaupun sudah online, masih bisa diedit dengan } \\
\text { leluasa. Tapi biasanya, editing hanya mencakup } \\
\text { masalah-masalah teknis, seperti merevisi salah } \\
\text { ketik, dan seterusnya. }\end{array}$ \\
\hline
\end{tabular}




\begin{tabular}{|c|c|c|}
\hline $\begin{array}{l}\text { Tugas desainer } \\
\text { atau layouter }\end{array}$ & $\begin{array}{l}\text { Tiap edisi, } \\
\text { desainer } \\
\text { atau layouter } \\
\text { harus tetap } \\
\text { bekerja untuk } \\
\text { menyelesaikan } \\
\text { desain pada edisi } \\
\text { tersebut. }\end{array}$ & $\begin{array}{l}\text { Desainer dan programmer cukup bekerja sekali } \\
\text { saja, yakni di awal pembuatan situs web. } \\
\text { Selanjutnya, tugas mereka hanya pada masalah- } \\
\text { masalah maintenance atau ketika perusahaan } \\
\text { memutuskan untuk mengubah desain dan } \\
\text { sebagainya. Setiap kali redaksi meng-upload } \\
\text { naskah, naskah itu akan langsung "masuk" ke } \\
\text { desain secara otomatis. }\end{array}$ \\
\hline Jadwal terbit & $\begin{array}{l}\text { Berkala (harian, } \\
\text { mingguan, } \\
\text { bulanan, dua } \\
\text { mingguan, dan } \\
\text { sebagainya). }\end{array}$ & $\begin{array}{l}\text { Kapan saja bisa, tidak ada jadwal khusus, kecuali } \\
\text { untuk jenis-jenis tulisan/rubrik tertentu. }\end{array}$ \\
\hline Distribusi & $\begin{array}{l}\text { Walau sudah } \\
\text { selesai dicetak, } \\
\text { media tersebut } \\
\text { belum bisa } \\
\text { langsung dibaca } \\
\text { oleh khalayak } \\
\text { ramai sebelum } \\
\text { melalui proses } \\
\text { distribusi. }\end{array}$ & $\begin{array}{l}\text { Begitu di-upload, setiap berita dapat langsung } \\
\text { dibaca oleh semua orang di seluruh dunia yang } \\
\text { memiliki akses internet. }\end{array}$ \\
\hline
\end{tabular}

Perkembangan teknologi informasi dengan segala konskuensinya sedang tumbuh dan berkembang sangat deras. Peradaban ini, menurut Toffler (1980), membawa gaya baru terhadap hampir semua aspek kehidupan manusia. Peradaban itu telah dan akan mengubah cara kerja, cara bergaul, cara bercinta, dan sebagainya pada semua lapisan masyarakat. Indonesia, diakui atau tidak, telah terbawa oleh arus peradaban informasi itu.

Alvin Toffler membagi tiga gelombang peradaban manusia. Pertama, saat manusia menemukan pola bercocok tanam menetap. Toffler menggambarkan pola menetap ini dinilai sebagai perubahan social yang luar biasa. Zaman di mana masyarakat yang sebelumnya berpindah-pindah (nomaden) dengan pola mata pencaharian meramu (food gathering) mentransformasikan diri menjadi masyarakat dengan mata pencaharian bercocok tanam. Ini jelas mempengaruhi hidup dan kehidupan social/budaya dan cara-cara mereka berkomunikasi. Ini jelas sebuah revolusi besar! Karena manusia mau mengubah kebiasaannya yang sudah berlangsung puluhan ribu tahun.

Kedua, gelombang peradaban yang dikenal dengan revolusi industri. Awal dari revolusi industri ini adalah adanya rangkaian inovasi/penemuan mesin cetak oleh J.Guttenberg para paro pertama abad ke-15. Dengan 
mesin cetak, hasil pemikiran seseorang dapat diperbanyak, kemudian baca oleh banyak orang. Segala macam pemikiran dan invention itu kemudian mengarah pada terjadinya berbagai inovasi. Dan, itu "meledak" menjadi revolusi industri. Kata kunci dalam peradaban gelombang kedua ini selain industri adalah 'kebiasaan membaca', menuliskan buah pikiran.

Ketiga, sejatinya Toffler belum meneukan kata yang tepat untuk mendefinisikan gelombang ketiga yang dialami manusia saat ini. Namun, sementara orang ada yang menyebut sebagai "abad informasi", abad ruang angkasa, atau abad elektronik. M.McLuhan menyebutnya "global village".

Analisa Toffler tersebut tidaklah terlalu keliru. Kini, dunia seolah menjadi kecil. Melalui berbagai media (massa maupun interaktif yang bersifat hybrid), apapun yang terjadi di satu sudut dunia bisa disampaikan ke belahan dunia lain. Media massa pun ada bermacam-macam, mulai dari bentuk cetak, online, audio, hingga audio visual. Lebih lengkap lagi, karena saat ini setiap media massa juga diperkuat dengan media social (facebook, Instagram, Twitter, WhatsApp, dll) untuk menyebarkan informasi.

Tak bisa dipungkiri, pengaruh atau peranan media massa dalam kehidupan social budaya dan politik dewasa ini sangatlah besar. Hanya saja, seberapa dan bagaimana proses berperannya dalam kehidupan bermasyarakat, masih perlu penelitian lebih lanjut.

Salah satu teori media, yakni teori konstruksionis, berita sebagai produk media memang tidak lebih sebagai konstruksi dari "fakta" di lapangan, bukan refleksi. Artinya, berita yang oleh khalayak baca setiap harinya bukanlah apa yang terjadi sungguh-sungguh di luar sana. Konstruksi mengandung arti bahwa bagaimana isi sebuah produk berita sangat bergantung dari bagaimana fakta tersebut dilihat dan dibingkai oleh pewarta atau institusi media. Nah, bagaimana institusi media bekerja dalam mengkonstruksikan berita tentu saja dipengaruhi oleh serangkaian faktor baik internal maupun eksternal.

Ahli komunikasi massa Harold D Lasswell dan Charles Wright, menyatakan terdapat empat fungsi sosial media massa, yaitu :

Pertama, sebagai social surveilance. Pada fungsi ini, media massa termasuk media televisi, akan senantiasa merujuk pada upaya penyebaran informasi dan interpretasi seobjektif mungkin mengenai peristiwa yang terjadi, dengan maksud agar dapat dilakukan kontrol sosial sehingga tidak terjadi hal-hal yang tidak diinginkan dalam lingkungan masyarakat bersangkutan.

Kedua, sebagai social correlation. Dengan fungsi korelasi sosial tersebut, akan terjadi upaya penyebaran informasi yang dapat menghubungkan satu kelompok sosial dengan kelompok sosial lainnya. Begitupun antara pandanganpandangan yang berbeda, agar tercapai konsensus sosial.

Ketiga, fungsi socialization. Pada fungsi ini, media massa selalu merujuk pada upaya pewarisan nilainilai luhur dari satu generasi ke generasi selanjutnya, atau dari satu 
kelompok ke kelompok lainnya.

Keempat, fungsi entertainment. Agar tidak membosankan, sudah tentu media massa perlu juga menyajikan hiburan kepada khalayaknya. Hanya saja, fungsi hiburan ini sudah terlalu dominan mewarnai siaran televisi kita, sehingga ketiga fungsi lainnya, seolah telah terlupakan. Untuk itu, fungsi hiburan haruslah ditata agar seimbang dengan 3 (tiga) fungsi lainnya.

Sejatinya, keempat fungsi media massa tersebut bersinergi dan sinkron dalam rangka menyajikan tontonan yang sehat. Sebab, hanya dengan tontonan yang sehat sajalah yang nantinya dapat melahirkan generasi yang sehat. Generasi yang memiliki karakter bangsa. Dalam hal inilah, kesadaran masyarakat dunia pada umumnya dan Indonesia secara khusus perlu bertekad dan berkomitmen untuk mengupayakan agar ke depan jangan lagi mau membiarkan diri dan keluarganya didikte oleh siaran TV yang tidak mendidik dan bahkan merusak pembangunan karakter bangsa bagi masyarakat (warga negara) dalam pembangunan bangsa ke depan.

Dari penjelasan di atas, dapat kita simpulkan bahwa peran media massa dalam mentransformasikan nilainilai kebangsaan merupakan suatu yang sudah seharusnya dan media kita sesungguhnya sudah dan terus melakukannya. Peran media massa dalam pembangunan karakter bangsa, haruslah berlandas pada perspektif budaya Indonesia yang meletakkan landasannya dalam kerangka negara kesatuan, dengan keanekaragaman budaya yang memiliki nilai- nilai luhur, kebijaksanaan dan pengetahuan lokal yang arif dan bijaksana (local wishdom and local knowledge). Media TV di Indonesia harus mampu menggali dan menjadikannya sebagai norma acuan atau tolok ukur di dalam melakukan penyiarannya.

Pada prinsipnya, paradigma pers merupakan kerangka berpijak bagi operasionalisasi perusahaan pers. Ashadi membedakan paradigm tersebut dalam dua kategori, yakni paradigma structural-fungsionalisme dan paradigm forum masyarakat. Pers dalam paradigm structuralfungsionalisme dipandang sebagai salah satu komponen penting dalam struktur social. Pada posisinya, pers berfungsi memilihara stabilitas dan harmoni antar-komponen yang lain dalam masyarakat dengan cara menyampaikan informasi. (Ashadi, 1991: 31-36)

Sementara berdasar paradigm kedua, pers berfungsi sebagai informing, influencing, entertaining and providing a marketplace for goods and services (Ashadi, 1991:40). Dalam pandangan ini, pers dituntut untuk dapat merespon kebutuhan khalayak atas media. Paradigma ini melihat fungsi pers dalam kerangka mikro, berbeda dengan paradigm structuralfungsionalisme yang memandang fungsi pers dalam kerangka makro. (Ashadi, 1991: 37)

Menimbang bahwa masyarakat kita telah semakin mengintegrasikan diri ke dalam sistem informasi global, di mana monopoli kebenaran oleh satu pihak tidak lagi dimungkinkan oleh karena berbagai alternatif sumber informasi serta versi informasi dapat 
dengan mudah diperoleh oleh setiap individu. Maka, pembatasan informasi oleh media mestinya tidak perlu terjadi. Apalagi, dengan canggihnya teknologi saat ini, pemerintah bisa mengontrol informasi tanpa harus membredel media. Pemerintah lewat Menteri Komunikasi dan Informasi, cukup mendorong agar media ikut berperan aktif dalam mengedukasi masyarakat dengan berita-berita yang mendidik dan inovatif.

\section{PENYEMPURNAAN KELENGKAPAN FASILITAS PRAKTIK}

Melihat kenyataan itu, mau tidak mau, Fakultas Dakwah dan Komunikasi UIN Walisongo yang menyiapkan sarjana kompeten di bidang media, haruslah tanggap terhadap kondisi itu. Bahwa, kini dunia media massa sudah berubah demikian pesatnya.

Sejatinya, Fakultas Dakwah dan Komunikasi (Fakdakom) UIN Walisongo telah memiliki modal awal, yakni tersedianya Gedung Laboratorium. Karena itu, butuh penyempurnaan di sana sini agar fungsi labroratorium bisa maksimal dan sesuai harapan. Selain itu, pengelolaannya tidak bisa sekadarnya. Sebab, labroratorium sebagai tempat praktik langsung bagi mahasiswa, menjadi kawah candradimuka dalam mematangkan skill mahasiswa. Tata kelolanya harus dilakukan secara profesional, terarah dan terukur.

Pihak fakultas sebenarnya bisa berkaca dari tempat kegiatan kuliah kerja lapangan (KKL) maupun praktik pengalaman lapangan (PPL) mahasiswa. Tentu saja tidak harus ideal sebagaimana yang dimiliki oleh perusahaan media tempat mahasiswa KKL maupun PPL. Namun, secara teknis, kita bisa melihat bagaimana pengelolaan radio, televisi, maupun media massa cetak dikelola secara profesional. Sehingga, kita bisa membandingkan apakah ruang praktik dan fasilitas, serta sumber daya manusia (SDM) yang ada di laboratorium sudah memadai atau belum.

Karena itu, rasanya tidak cukup bila Fakultas Dakwah dan Komunikasi dalam rangka meningkatkan bargaining position lulusannya dengan "hanya" sekadar mengganti gelar sarjana dari Sarjana Sosial Islam (S.Sos.I) menjadi Sarjana Sosial (S.Sos) saja, tanpa membekali skill yang memadai. Apalah artinya sebuah nama gelar akademik, bila pada kenyataan kualitas lulusan sama dengan yang sebelumnya.

Penghilangan huruf "I" pada gelar akademik Fakdakom, justru menjadi kerugian besar. Sebab, itu sebagai sebuah identitas sekaligus kebanggaan bagi lulusan Universitas Islam Negeri (UIN) Walisongo yang masih memegang prinsip-prinsip keilmuan Islam. Justru, keunggulan lulusan UIN, karena ada identitas "Islam"-nya.

Bisa diibaratkan, pada sosok wanita yang memakai jilbab misalnya! Untuk mempercantik si wanita, tentu kita tak perlu harus meminta wanita itu untuk melepas jilbab/hijabnya. Yang perlu dilakukan adalah bagaimana memodifikasi jilbabnya sehingga bisa terlihat menarik, tidak monoton lagi. Artinya, bila si wanita yang memakai 
hijab dasarnya sudah cantik, mau dipakaiin model hijab seperti apapun, mulai dari yang modern maupun jadul, tetap saja akan terlihat cantik.

Akan berbeda, manakala si wanita yang memakai hijab dari sisi wajahnya kurang menarik. Maka, yang harus dilakukan adalah dengan memodifikasi model hijabnya sehingga meski dari sisi wajah kurang menarik, tetap bila hijabnya dimodifikasi sedemikian rupa, maka niscaya si wanita yang sebelumnya kurang menarik itu akan terlihat anggun dan cantik.

Demikian halnya dengan mahasiswa, bila dasarnya dia sudah pintar, anaknya kreatif dan pandai bersosialisasi, kelak pasti akan menjadi lulusan yang mampu bersaing secara kompetitif di dunia kerja/ masyarakat. Yang perlu dilakukan terhadap mahasiswa model seperti ini adalah cukup dengan membekali skill agar kepercayaan diri makin tumbuh.

Sementara bagi mahasiswa yang dari dasarnya memang kurang begitu pandai, tidak kreatif, dan tidak pandai bersosialisasi, maka menjadi tanggung jawab pihak akademisi untuk memolesnya agar bisa setara atau sepadan dengan mahasiswa pandai di atas. Untuk membuat mahasiswa seperti ini agar kelak bisa berkompetisi dan memiliki bargaining di dunia kerja, maka butuh pemolesan skill sesuai bakat yang dimilikinya. Rasanya, Fakdakom memiliki jurusanjurusan yang sangat kompeten di bidangnya untuk menggembleng dan menjadikan mahasiswa model kayak gini.

Dengan model penanganan seperti itu, sejatinya pihak pengambil kebijakan tidak perlu terburu-buru dalam menghilangkan "I" dalam gelar akademik lulusan Fakdakom. Sebab, bila melihat fakta di lapangan, para lulusan UIN Walisongo secara umum, dan Fakdakom khususnya, tetap mampu bersaing dalam dunia kerja dari lulusan perguruan tinggi lainnya. Mereka tersebar dalam berbagai profesi dan mampu menduduki posisiposisi strategis. Karena itu, kita tidak perlu minder (rendah diri) terhadap gerlar yang tersemat sebagai lulusan dari perguruan tinggi Islam.

Hal yang perlu dilakukan dalam menjawab tantangan "dunia kerja" ataupun persaingan dengan perguruan tinggi lainnya adalah menyadari bahwa saat ini merupakan era digital. Di mana, para pemangku kebijakan, harus melihat fakta itu untuk menyesuaikan diri, sehingga Fakdakom tidak tertinggal dari perguruan tinggi lainnya dalam soal teknologi digital. Pemaksimalan laboratorium dakwah perlu diseriusi lagi dalam rangka mempersiapkan mahasiswa agar tidak gagap teknologi (gaptek).

Perubahan peta media massa yang kini memanfaatkan teknologi digital juga harus disikapi dengan memperkuat SDM para dosen. Era cross media atau konvergensi media, telah dimulai! Media online, tak sekadar mampu menyajikan teks dan foto, tetapi video dan e-paper, mampu disajikan sekaligus.

Karena itu, jangan sampai timpang, di mana masih ada dosen yang gaptek dan tertinggal jauh dengan mahasiswanya. Kalau ini terjadi, jelas sesuatu yang tak lucu. Karena itu, laboratorium yang ada, 
tak hanya sekadar menjadi "kawah Candradimuka" mahasiswa tetapi juga untuk dosen. Untuk itu, kelengkapan fasilitas laboratorium dakwah adalah sebuah keniscayaan!

Memasuki era digital ini, di mana dominasi media online makin tak terbendung, maka upaya-upaya mensinergikan matakuliah dengan dunia digital tak bisa dielakkan lagi. Matakuliah yang ada, semaksimal mungkin harus mampu menjawab tantangan ini. Misal matakuliah tentang "Pengantar Ilmu Dakwah". Bagaimana matakuliah ini tak hanya sekadar menjelaskan tentang teoriteori ilmu dakwah saja, tetapi juga bagaimana cara berdakwah lewat multimedia! Dengan begitu, teoriteori dakwah yang tekstual mampu terimplementasikan dalam dakwah yang kontekstual, sehingga teori-teori dakwah mampu diterima masyarakat yang sudah melek teknologi. Begitupun dengan matakuliah lainnya, semua harus tersinergikan dengan multimedia.

Adanya model rencana perkuliahan semester (RPS) yang mulai diterapkan di lingkungan UIN Walisongo, tak terkecuali di Fakdakom, mendorong mahasiswa maupun dosen harus kreatif dan tidak ketinggalan teknologi. Target-target pada setiap pertemuan perkuliahan sasarannya mulai jelas. Semua harus terkonsep rapi dan pada muaranya menghasilkan mahasiswa, yang tak hanya paham terhadap apa yang dipelajarinya tetapi juga tahu cara bagaimana mengimplementasikan setiap matakuliah yang dipelajari sesuai konteks zaman.

DenganmodelRPSini,mahasiswa yang mengambil matakuliah keahlian, maka akan semakin terasah skill-nya. Hal ini menjadi keuntungan tersendiri bagi Fakdakom yang memang mempersiapkan mahasiswanya ahli dalam bidang media (multimedia). Tak terelakkan, praktik-praktik mandiri atau kelompok di setiap matakuliah, akan semakin mempertajam skill mahasiswa. Tak ada lagi alasan mahasiswa malas mengerjakan tugastugas lapangan, sebab ini sudah menjadi satu prasyarat bagi mereka untuk menggali bakat "tersembunyi". Ini sesuai dengan karakteristik industri media yang membutuhkan tenaga-tenaga terampil, siap pakai, dan mumpuni di lapangan.

Keuntungan lainnya lagi, adalah industri media makin berkembang pesat, baik itu cetak, online, maupun elektronik. Industri media ini tentu saja membutuhkan SDM yang memiliki karakter di atas. Peralihan era manual ke digital ini, harus ditangkap sebagai sebuah peluang bagi Fakultas Dakwah dan Komunikasi. Sebab, lapangan kerja bagi lulusan Fakdakom makin terbuka luas dan banyak pilihan. Secara otomatis, keberadaan Fakdakom menjadi sangat penting dalam mempersiapkan SDM di bidang media.

Karena itulah kenapa menyempurnakan berbagai fasilitas penunjang perkuliahan, seperti halnya keberadaan Laboratorium Dakwah yang lengkap, menjadi sangat penting dan tak terelakkan lagi. Sebab, mengubah sesuatu kalau hanya dari kulitnya saja akan sia-sia, harus menyeluruh! Bidang pada isinya harus dibenahi dulu agar semua tak hanya terlihat manis dari luarnya saja tetapi 
juga dalamnya.

Niscaya, bila hal itu mampu terwujud dengan baik, maka tidak mustahil ke depan Fakdakom akan menjadi fakultas favorit dan menjadi pilihan bagi calon mahasiswa yang akan menuntut ilmu di UIN Walisongo Semarang. Tanpa pembenahan itu semua, maka mustahil Fakdakom akan mampu menjawab tantangan era digital ini! (*)

\section{REFERENSI}

Lev Manovich is Professor of Visual Arts, University of California, San Diego. His book The Language of New Media (MIT Press, 2001)

http://prima-iamcome.blogspot. co.id/2011/09/digital-theory-teoridigital

Teguh Kresno Utomo, S.IP: Produksi Media Cetak,Posted on Oktober 25, 2009

http://reskymaulana ofc. blogspot.co.id: Pengertian Teknologi Berbasis Digital

M. Ridlo 'Eisy: Masa Depan Media Cetak di Indonesia (artikel, 2009)

Don Sabdono: Senjakala Media (Kompas, 2015)

Rustam Aji: Antara Media Massa dan Politik Media (Missi, 2013)

Industri Pers dan Prospek Kebebasannya (Jurnal Ikatan Sarjana Komunikasi Indonesia, VOL V/ Oktober 2000)

Ashadi Siregar: Pers, Jurusan
Ilmu Komunikasi Fisipol UGM Yogyakarta, 1992

Jonru, Perbedaan Antara Media Massa Cetak dengan Media Massa Online (Internet, 2008) 